\title{
Ice-supersaturated regions and subvisible cirrus in the northern midlatitude upper troposphere
}

\author{
Klaus Gierens and Ulrich Schumann \\ Deutsches Zentrum für Luft- und Raumfahrt, Institut für Physik der Atmosphäre \\ Oberpfaffenhofen, Germany \\ Manfred Helten and Herman Smit \\ Forschungszentrum Jülich, Institut für Chemie der belasteten Atmosphäre (ICG2), Jülich \\ Germany \\ Pi-Huan Wang \\ Science and Technology Corporation, Hampton, Virginia
}

\begin{abstract}
Humidity and temperature data from the Measurement of Ozone by Airbus in-service Aircraft (MOZAIC) project have been used to produce maps of probability for ice supersaturation in two $50 \mathrm{hPa}$ thick layers centered around 200 and $250 \mathrm{hPa}$. As the MOZAIC data cover only international air routes, the resulting maps cover mainly the northern midlatitudes. The data of ice supersaturation have then been correlated with data of frequency of occurrence of subvisible cirrus from the Stratospheric Aerosol and Gas Experiment (SAGE II) satellite instrument. The correlation analysis provided strong indications that subvisible cirrus (SVC) is associated to ice-supersaturated regions (ISSRs), although processes are possible that can decouple SVC from ISSRs. A first trial to derive a global picture of ice supersaturation near the tropopause was performed using a measure of cirrus fractional coverage constructed from meteorological analyses of European Centre for Medium-Range Weather Forecasts and to correlate this with the supersaturation data. The correlation was only moderate (although significant), leading to the tentative conjecture that regions of frequent ice supersaturation are to be expected over the Indonesian archipelago, over the Amazonas basin, and over the northern Pacific between Japan and Canada. A final correlation analysis between the meteorological analysis data and the SVC data indicated that the formation of SVC is generally thermodynamically controlled, with the exception of the northern midlatitude SVC. The composition of the aerosol at the northern midlatitude tropopause is probably variable due to industrial emissions and air traffic. Hence the freezing properties of these particles may become important, which results in a weaker thermodynamic control of SVC formation in the northern midlatitudes.
\end{abstract}

\section{Introduction}

The realization that ice supersaturation must be frequent in the upper troposphere is more than 50 years old. Helmut Weickmann concluded already in his 1945 review paper on "Shapes and formation of atmospheric ice crystals" [Weickmann, 1945] that ice crystals in the atmosphere, that is, cirrus clouds, form mainly via the water phase and not as soon as ice saturation is reached. He characterized the ice-forming regions in the upper troposphere (and he even included the stratosphere here!) as regions of high ice supersaturation but with

Copyright 2000 by the American Geophysical Union.

Paper number 2000JD900341.

0148-0227/00/2000JD900341\$09.00 small absolute humidity. It seems that the existence of ice-supersaturated regions (ISSRs) has been deemed unimportant for numerical weather prediction and climate modeling for a long time. Only since about the last 10-15 years the interest in upper tropospheric moisture is growing among the scientific community, mainly because it has been realized that the upper tropospheric humidity, in spite of its small contribution to the total atmospheric water content, plays an important role in the radiation budget of the Earth [e.g., Ramanathan and Collins, 1991], and the question whether the water vapor in the upper troposphere modifies the climate via positive or negative feedbacks is a topic of lively debate [e.g., Lindzen, 1990; Rind et al., 1991].

More recent indications of ice-supersaturated regions in the upper troposphere came from cirrus formation re- 
search and contrail research. From many measurements in wave clouds, Heymsfield et al. [1998] have determined a critical relative humidity necessary for ice nucleation as a function of ambient temperature. At low temperature these critical relative humidities imply substantial ice supersaturation. The frequent occurrence of ice-supersaturated air masses in the upper troposphere and the tropopause region has been found by in situ measurements also over oceanic regions [Ovarlez et al., 2000; Helten et al., 1999; Schumann et al., 2000]. Obviously, there is a range of humidity values between ice saturation and the critical relative humidity that allows formation of visible cirrus clouds. Upper tropospheric regions with a relative humidity in this range appear clear from ground and therefore did not attract much attention so far. However, these regions might be important in several respects, for instance the following: they may be the sources of sub visible cirrus and hence they may have an impact on the radiation budget of the Earth. Via the change of vertical radiation flux divergence these regions may affect the height of the local tropopause [Thuburn and Craig, 1997].

Aircraft condensation trails (contrails) can form and persist at supersaturations too low to support cirrus nucleation since the water vapor released from the aircraft engines mixes with the ambient air in a way that can lead in the aircraft wake temporarily to huge supersaturation, thereby allowing nucleation [Schumann, 1996]. Contrails in clear air are thus able to mark the supersaturated regions where the ambient humidity is not yet sufficient for formation of cirrus clouds. Contrails often appear in groups that have typical diameters of several 100 to $1000 \mathrm{~km}$ and usually last for more than a day [Bakan et al., 1994; Carleton and Lamb, 1986]. It is most plausible to assume that these groups occur in coherent regions with ice supersaturation, that is, regions where the state of the atmosphere allows the formation of persistent contrails [Mannstein et al., 1999]. Sausen et al. [1998] determined the global distribution of regions in the upper troposphere where contrail formation is possible. The so-called "potential contrail cover" has a global mean value of $16 \%$ for the current climate. This number might be an upper boundary for the possible area fraction of regions with ice supersaturation; it had been derived from European Centre for Medium-Range Weather Forecasts (ECMWF) reanalyses using a contrail and cirrus parameterization scheme and is consistent with estimates from the satellite data evaluation scheme of Mannstein et al. [1999]. Yet the determination of potential contrail cover is not based on direct humidity measurements in the upper troposphere so far.

Direct evidence for the existence of ice-supersaturated regions in the clear upper troposphere over large portions of the globe comes from the recent evaluation of water vapor data from the Measurement of Ozone by Airbus In-service Aircraft (MOZAIC) project [Marenco et al., 1998]. Gierens et al. [1999] found that $13.5 \%$ of these data implied ice supersaturation. The mean su- persaturation in such moist regions is $15 \%$, whereas the mean critical relative humidity for cirrus formation according to Heymsfield et al. [1998], (see above) and for the mean temperatures of such regions turned out to imply an ice supersaturation of about $30 \%$. This finding explains that ice-supersaturated regions are often not recognizable from ground, since they appear in clear air, unless air traffic marks them with persistent contrails. The degree of supersaturation in these moist regions obeys a simple probabilistic distribution law, it is exponentially distributed, which implies that small supersaturation is much more probable than a large one [Gierens et al., 1999]. This is consistent with empirical statistics of contrail types found by Sussmann and Gierens [1999].

In the present paper we will evaluate the MOZAIC data further, in order to determine the spatial distribution of ice supersaturation in the upper troposphere. In section 2 we will present maps of the relative frequency (or probability) of ice supersaturation for two pressure ranges. In section 3.1 we will study the relation between ice-supersaturated regions (ISSRs) and subvisible cirrus (SVC). Data about SVC are taken from the Stratospheric Aerosol and Gas Experiment II (SAGE II) satellite [Wang et al., 1996]. Such a study serves two purposes: First, from a radiation point of view, ice supersaturation can only be distinguished from subsaturation when ice crystals are formed in the ISSR. Supersaturation alone does not produce particular spectral signatures. Thus a positive correlation between ISSR and SVC would make remote sensing and detection of ISSRs easier. Such a correlation could then be used to complete the maps of section 2 (which are void of data where no MOZAIC flights took place). Second, the existence or non-existence of a correlation between ISSR and SVC provides constraints for the formation mechanisms of SVC in midlatitudes. Since the MOZAIC data are confined to regions of heavy international air traffic, we seek for a possibility to predict regions of frequent ice supersaturation off the MOZAIC air routes. A positive correlation between ISSR data and data of the upper tropospheric humidity field or cirrus distribution would allow such inferences. In section 3.2 we use a measure of cirrus distribution constructed by Sausen et al. [1998] from the ECMWF reanalyses [Gibson et al., 1997] for this purpose. Finally, we compare also the SAGE II SVC data with ECMWF reanalysis data. This comparison will give valuable insight into the question whether SVC formation is controlled by thermodynamics or by the availability of aerosol particles suitable for nucleation at small supersaturation. We summarize the results and draw conclusions in section 4 .

\section{Spatial Distribution of Ice-Supersaturated Regions}

In order to allow spatial statistics with the MOZAIC data, they have been gridded onto a T42 grid, as has been done in our earlier work on large-scale humidity 
and temperature fluctuations [Gierens et al., 1997]. In T42 resolution the zonal direction is divided into 128 sectors, the meridional direction into 64 segments, giving a total of 8192 grid cells. A T42 cell has a dimension of $2.8^{\circ} \times 2.8^{\circ}$, that is, about $300 \times 300 \mathrm{~km}^{2}$. We use only data obtained in the pressure range $175-275 \mathrm{hPa}$ and sort them into two $50 \mathrm{hPa}$ thick layers centered around 200 and $250 \mathrm{hPa}$. The hygrometers aboard the MOZAIC aircraft are capacitive sensors (Humicap $\mathrm{H}$, Vaisala, Finland). The water vapor measurement system, its installation, working principle, and calibration is described in detail by Helten et al. [1998] and will not be repeated here. The humidity data on the MOZAIC database are of varying quality; here we only consider data that have been qualified reliable (validity tag "1" on the database). Absolute uncertainties and absolute precision for the used data are given in section 2 of our previous paper [Gierens et al., 1999]. The measurements have been successfully compared with other in-flight measurements [Helten et al., 1998, 1999]. Relative humidities with respect to ice can be computed from the measured relative humidity with respect to liquid water almost without introducing an additional error due to temperature uncertainties because the ratio of the two saturation water vapor partial pressures varies only weakly with temperature (e.g., between $60^{\circ} \mathrm{C}$ and $-61^{\circ} \mathrm{C}$ by $0.5 \%$ which is much smaller than the uncertainty of the humidity measurement itself). In order to simplify data evaluation we devise a binary quantity $I C$ that obtains the value 1 when there is ice supersaturation and zero otherwise.

We want to compute from the MOZAIC data a map showing the probability of ice supersaturation as a function of longitude, latitude, and altitude. We proceed in the following way: we consider each flight separately. If a flight was for 8 or more minutes in a certain grid cell (which implies that the distance flown in this cell was $100 \mathrm{~km}$ or longer), the measurements in this grid cell are stored for later averaging. Measurements in grid cells with less than $8 \mathrm{~min}$ flight time are discarded from the further evaluation since we do not consider a flight distance of less than $100 \mathrm{~km}$ in a $300 \times 300 \mathrm{~km}^{2}$ cell representative. Next we take the set of grid cells that remain after the previous step and discard all grid cells that have not been met by at least 30 flights during the 3 year period (1995-1997) of MOZAIC measurements. This filters out grid cells that have only sporadically been met by MOZAIC flights (e.g., only in a certain season of the year or otherwise incidentally). The remaining grid cells have been sampled in all 3 years with a relative constant frequency throughout the year. We find 417 cells in the $200 \mathrm{hPa}$ layer and 497 cells in the $250 \mathrm{hPa}$ layer that remain after the sort-out procedure. For these cells we have determined the number of measurements that indicate ice supersaturation. The ratio of this number and the total number of measurements in a cell, $P\{I C=1\}$, may be considered the relative frequency or probability of ice supersaturation. The result of this procedure is shown in Plate 1.
One should note the difference between the probability of ice supersaturation $P\{I C=1\}$ and the probability for a certain degree of ice supersaturation that has been mentioned in the introduction. The letter quantity is $P\left\{n \% \leq R H_{i}<(n+1) \%\right\} ; n \geq 100$, that is, the probability that $R H i$ obtains a value in the range $[n, n+1) \%$, whereas $P\{I C=1\} \equiv P\{R H i \geq 100 \%\}$. In order to avoid confusion we will often call $P\{I C=1\}$ in the following the "fractional coverage of ice supersaturation" which is another possible interpretation of this quantity.

The overall probability of ice supersaturation is larger in the $250 \mathrm{hPa}$ layer than in the $200 \mathrm{hPa}$ layer. The mean values are $11.2 \pm 5.6 \%$ for the $200 \mathrm{hPa}$ layer and $15.2 \pm 7.0 \%$ for the $250 \mathrm{hPa}$ layer. Note that these numbers refer only to the valid pixels in Plate 1; the actual global means are unknown since no appropriate database for their determination exists. The driest location (i.e., the one with least fractional coverage of ice supersaturation of less than $1 \%$ ) in the lower layer is over a portion of the Sahara, whereas values of $20 \%$ and higher are not uncommon in more northern latitudes. The maximum fractional coverage of ice supersaturation of $36 \%$ is found about $10^{\circ}$ west of Brittany in France. In the $200 \mathrm{hPa}$ layer the pixel with largest fractional coverage of ice supersaturation (33\%) is found over equatorial Africa. Other candidate regions for high probability of ice supersaturation like the Amazonas region and the Indonesian archipelago are unfortunately not present in our database. Unlike the $250 \mathrm{hPa}$ layer, in the $200 \mathrm{hPa}$ layer the more northern latitudes tend to show low fractional coverage of ice supersaturation. The driest regions in this sense (supersaturation probabilities less than 1\%) are found at the northeast coast of Canada (Davies strait), in the North Atlantic between the southern cape of Greenland and the sea south of Iceland, over the Black Sea, and along the coast of the western Sahara.

When we consider all validity tag 1 and 2 (i.e., $R H$ less than detection threshold of $5 \%$ ) MOZAIC humidity data (i.e., not only those data that were used for construction of the maps), we find only a weak seasonal variation of the probability for ice supersaturation between $12.2 \%$ in spring and $15.9 \%$ in fall. (The corresponding numbers given by Gierens et al., [1999] are wrong because there we have erroneously only counted the data for one year, 1995.) We did, however, not produce seasonal maps of $P\{I C=1\}$ since we believe this should be done with a timeseries of 4 or 5 years of the database.

Gierens and Spichtinger [2000] have tried to determine the extents of ice-supersaturated regions (ISSRs) from the MOZAIC data. They found that MOZAIC aircraft flew a mean distance of $150 \mathrm{~km}$ within ISSRs, which spatial scale compares well with the typical extension of contrail clusters seen on satellite pictures [Bakan et al., 1994; Mannstein et al., 1999]. However, these authors showed also that the path length statistics is subject to a severe selection bias, namely, that the chance 

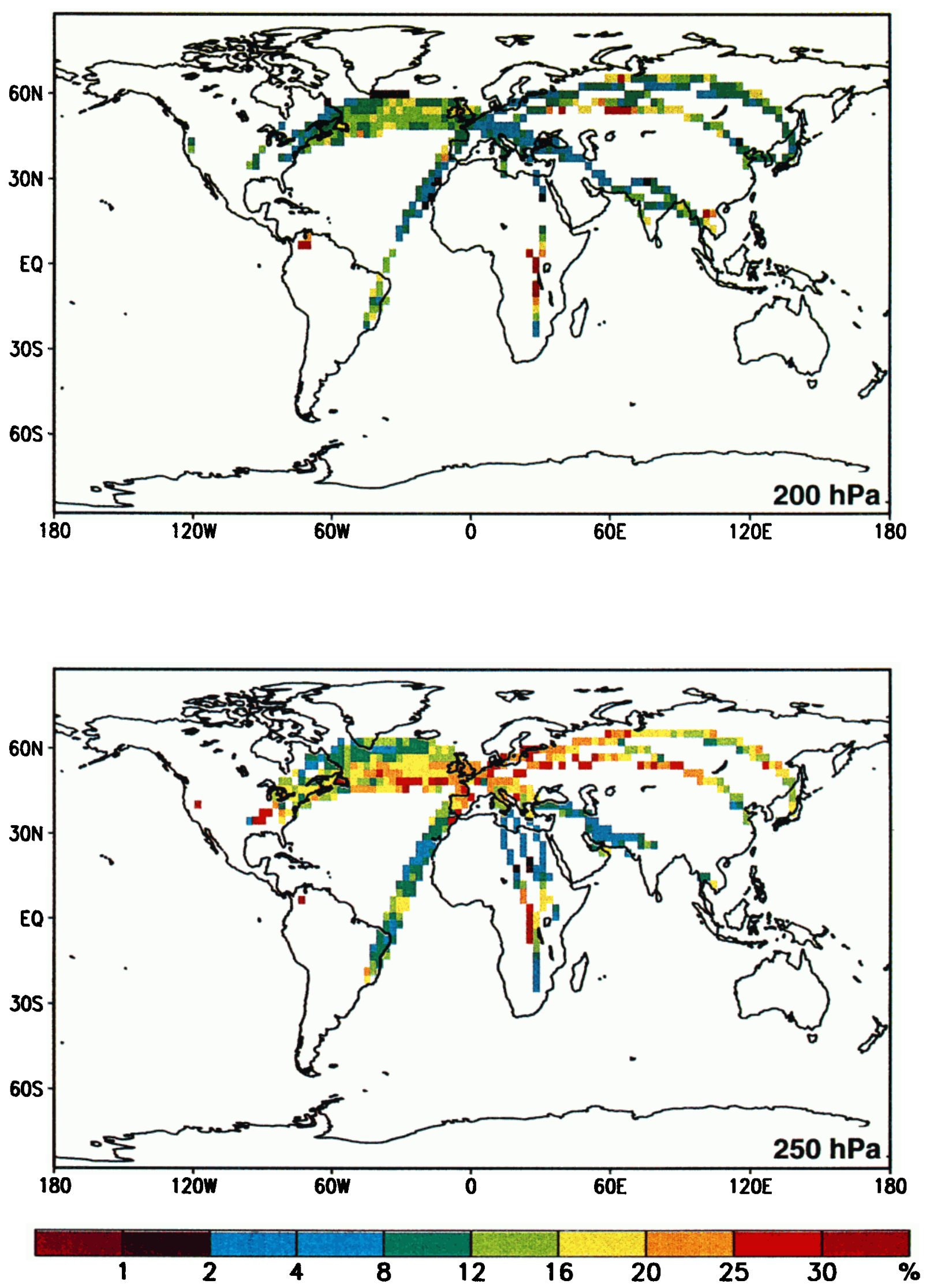

Plate 1. Relative frequency in percent of ice supersaturation $\left(R H_{i} \geq 100 \%\right)$ obtained from humidity and temperature measurements of the MOZAIC project during the years 1995-1997. Two $50 \mathrm{hPa}$ thick layers centered around 200 and $250 \mathrm{hPa}$ are shown. The statistics have been performed on a T42 spatial grid. 
of an ISSR to be crossed by an aircraft increases with its size. Unfortunately, this bias makes the path length statistics meaningless, and there is the possibility that most of the ISSRs are an order of magnitude smaller than the $150 \mathrm{~km}$ mean path length. A determination of the true extents of ISSRs requires dedicated research flights or advanced remote sensing techniques. One idea in the last respect is that ISSRs might often contain subvisible cirrus that, in turn, could be detected by satellite instruments. Thus it is interesting and important to study the correlation between ISSRs and subvisible cirrus, which we are now going to do.

\section{Correlation Analyses}

We must make a remark before we proceed. Ideally, one would like to correlate the occurrence of SVC and the existence of ice supersaturation on a case by case basis, that is, we would like to consider single events in space and time. Unfortunately, this is not practicable with the present data although time and space information could in principle be obtained from both MOZAIC and SAGE data. Single events cannot be used here because it is rather unlikely that one of the five MOZAIC aircraft and SAGE II measure the same region at the same time. It would be tedious to search such congruences in the data, in particular because SAGE II is a limb scanner, and yet the resulting data pool would probably be sparse. Therefore we consider the mean fields instead of single events, although the resulting database is not large and the results can be interpreted only in a statistical sense. In spite of this we deem the correlation analysis useful, also for inspiring more dedicated research on the relation between ISSRs and SVC (e.g., research aircraft flights synchronized with satellite overpasses).

\subsection{Correlation Between Ice Supersaturation and Subvisible Cirrus}

Subvisible cirrus (SVC) generally concentrates near the tropopause. It occurs most frequently in the tropics (associated with deep convection), yet a secondary maximum occurs at latitudes north of $30^{\circ} \mathrm{N}$ in an altitude range from 6 to $12 \mathrm{~km}$ [Wang et al., 1996]. Midlatitude SVC is probably associated with cold fronts, orographic forcing, or even contrail generated [Schmidt et al., 1993]. According to Sassen et al. [1989], SVC is characterized by an optical thickness of less than 0.03 . Other SVC characteristics are less clear: Whereas Sassen et al. [1989] find depolarization ratios lower than 0.2 for SVC, Lynch [1993] gives a range of 0.5-0.8. Ice contents are less than $1 \mathrm{mg} / \mathrm{m}^{3}$, most ice crystals are small $(<10 \mu \mathrm{m})$, but nonspherical, although larger ice crystals $(20 \mu \mathrm{m})$ seem to be present occasionally, as indicated by corona effects [Sassen and Cho, 1992]. Whether there are submicron particles (ice, haze) in SVC is not known.
Simulations of Jensen et al. [1996] gave a short lifetime of only a couple of hours for midlatitude SVC. This lifetime is much shorter than the lifetime of contrail clusters at midlatitudes (1-2 days [Bakan et al., 1994; Carleton and Lamb, 1986]) which we may take as an estimate of the lifetime of ISSRs. If the numerical result of Jensen et al. would be confirmed by direct observations, then one must conclude that midlatitude SVC can only be a transient phenomenon in ISSRs.

The assumption that SVC needs ice supersaturation and hence is associated with ISSRs is certainly plausible. However, so far no in situ measurements of SVC at midlatitudes have been published that could corroborate this conjecture. Using the MOZAIC data of ISSR together with the SAGE II data of SVC [Wang et al., 1996] makes it possible to indirectly confirm the assumption, using a correlation analysis. For this purpose we have used the SAGE II SVC data for altitudes of 10.5 and $12.5 \mathrm{~km}$. These two levels are closest to the 250 and $200 \mathrm{hPa}$ pressure levels that we have used for the evaluation of the MOZAIC data. Since the SAGE II data are gridded onto a $24^{\circ} \times 10^{\circ}$ (longitude $\times$ latitude) grid, we had to smooth the MOZAIC data from T42 resolution to the SAGE II spatial resolution. In the result we have retained only SAGE II grid points where 10 or more MOZAIC grid cells with a quantified value of $P\{I C=1\}$ (i.e., the colored pixels of Plate 1) can be used to calculate the smoothed mean. We chose this kind of averaging for the MOZAIC data in order to get a better spatial coverage of the large $24^{\circ} \times 10^{\circ}$ boxes than would be guaranteed with averaging the original $1-$ min data. Thus we retained 13 and 18 SAGE II grid cells for the 200 and $250 \mathrm{hPa}$ layers, respectively, to perform the correlation analysis. These SAGE II grid cells contain data from 10 to 35 valid MOZAIC T42 grid cells and they all belong to the northern middle latitudes, hence the following results refer to this zone.

The correlation coefficients (see Figure 1 for a scatterplot and least squares fits) are as follows: Considering only the $200 \mathrm{hPa}(12.5 \mathrm{~km})$ layer, the correlation coeffcient between the SAGE II frequency of subvisible cirrus and the fractional coverage of ice supersaturation from MOZAIC data is $r=0.45$, with an error probability (i.e., the probability that the data are actually uncorrelated in spite of the result $r \neq 0$ ) of $12 \%$. This relatively low significance is a consequence of the sparse database $(N=13)$ we have for the upper of the two layers. For the lower layer $(250 \mathrm{hPa}, 10.5 \mathrm{~km})$ the correlation is $r=0.71$ with an error probability of less than $0.1 \%$. The correlation is even stronger when we consider both layers together, that is, when we disregard the altitude. With a database of 31 grid cells we get then $r=0.77$ with a negligible statistical error probability.

The analysis gives indeed a strong indication for an association of SVC with ISSRs, at least in a statistical sense: Where the fractional coverage of icesupersaturation is high, the frequency of occurrence of 


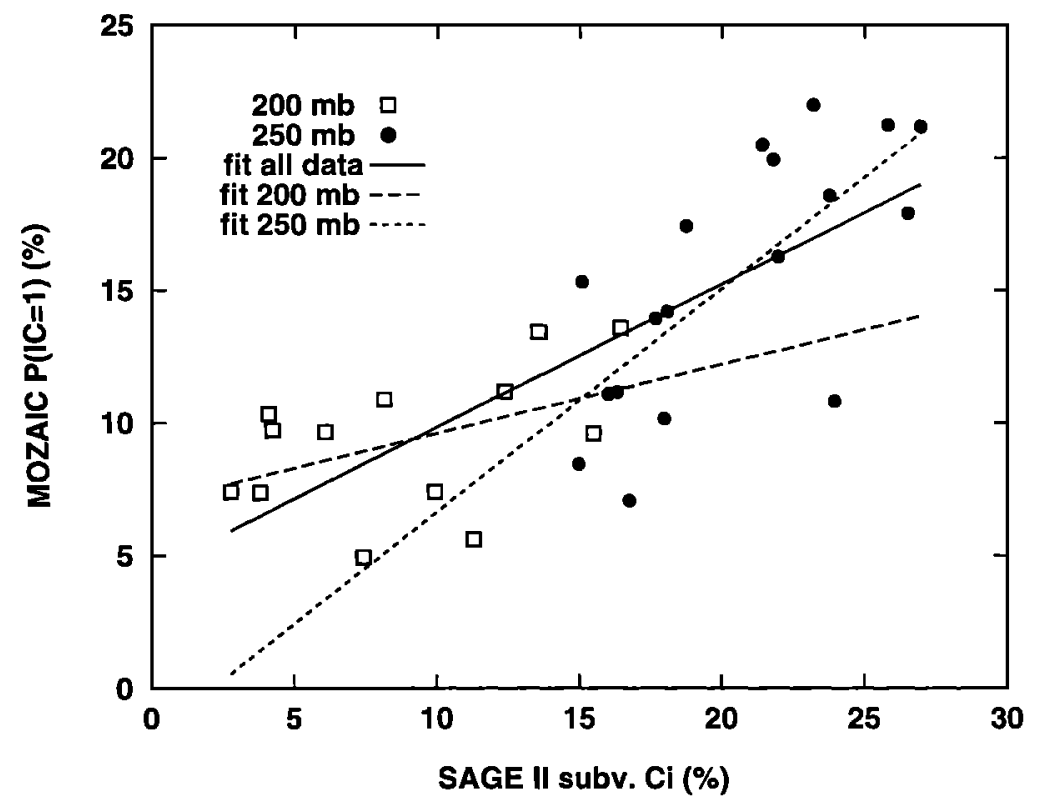

Figure 1. Scatterplot of SAGE II frequency of subvisible cirrus versus the probability of ice supersaturation from MOZAIC data in the layers centered around $12.5 \mathrm{~km}$ and $200 \mathrm{hPa}$ (open squares) and $10.5 \mathrm{~km}$ and $250 \mathrm{hPa}$ (solid circles). The straight lines represent least squares fits, using all data (irrespective of pressure and altitude, solid), and using only data from single layers (12.5 km, $200 \mathrm{hPa}$, long-dashed; $10.5 \mathrm{~km}, 250 \mathrm{hPa}$, short-dashed).

SVC is high, and vice versa. The correlation results do not allow statements about the association of SVC with ISSRs on a case by case basis, as explained before. It might be that the correlation analyzed with single events would be weak for two reasons: (1) An ISSR could have lost its ice crystals through precipitation and yet stay in an uplifting air mass, thereby adiabatically cooling and enhancing the supersaturation. Such a transient SVC is in particular conceivable in the upper troposphere of the midlatitudes, where the relatively warm air (compared with its tropical counterpart) and the probably small number of ice crystals nucleating at slight ice supersaturation lead to large growth rates in an uplifting air mass, which eventually results in sedimentation. (2) On the other hand, the sedimenting ice crystals could fall out of the ISSR into subsaturated air and easily reach falling distances of $2 \mathrm{~km}$ [Hall and Pruppacher, 1976]. Such processes could decouple SVC from ISSR and contribute to the scatter of the mean value data in Figure 1. Another contribution to the scatter may be due to the possibility that there are also more opaque cirrus clouds (optical thickness slightly larger than 0.03 ) associated with ISSRs, which would result in a convoluted SAGE II identification. Also the varying composition of the aerosol on which SVC ice crystals nucleate may contribute to the scatter of the data around the least squares fit lines.

Most points in Figure 1 are on the right of the diagonal $(y=x)$. This means that the relative frequency of occurrence of SVC somewhere in a $24^{\circ} \times 10^{\circ}$ grid box is usually higher than the fractional coverage of ice supersaturation in T42 grid boxes (i.e., $2.8^{\circ} \times 2.8^{\circ}$ ), averaged over the coarser SAGE grid. To compute also a fractional coverage of SVC would require the "amount when present" which we do not have at hand. So we had to compare and correlate different quantities and should therefore not expect the data points to scatter around a diagonal. There are also a few points with low SVC frequency (around 5\%) above the diagonal. All these points belong to the $200 \mathrm{hPa}$ layer which in the midlatitude is often part of the lowermost stratosphere. The probable explanation for these points is that SVC is rare and short-lived above the tropopause which makes its detection difficult, whereas ice supersaturation is possible there [Murphy et al., 1990] and may be long-lived because it can be associated to synoptic phenomena [Gierens et al., 1999]. The rareness of SVC in the lowermost stratosphere may also explain the finding from Figure 1 that the relative frequency of occurrence of SVC is usually higher in the $250 \mathrm{hPa}$ level than in the $200 \mathrm{hPa}$ layer in the northern midlatitudes. Another possible reason for these findings could be the settling of SVC ice crystals: This would lead to an ISSR in a higher level and to a SVC in a lower one and could hence explain why the "all data" fit in Figure 1 is less steep than the diagonal.

\subsection{Correlation Between Ice Supersaturation and Cirrus From Reanalyses}

Unfortunately, the MOZAIC data cover only a limited portion of the globe, and most of the world maps 
of Plate 1 is void of data. A strategy to fill these voids is to correlate the MOZAIC data with data sources of upper tropospheric humidity or cirrus cloudiness and to use the found correlations to infer those locations off the MOZAIC air routes where ice supersaturation in clear air might be frequent. For this purpose we had at hand a data set of cirrus coverage that has been constructed from an 11-year period (1983 to 1993) of ECMWF reanalysis data [Gibson et al., 1997] by Sausen et al. [1998] in order to test their global distribution of the potential contrail coverage. These data have been correlated with the MOZAIC data (as before only in those grid cells where $P\{I C=1\}$ is defined). The correlation coefficients are 0.30 and 0.31 in the 200 and $250 \mathrm{hPa}$ layers, respectively, which are quite moderate values although they are highly significant (i.e., the hypothesis that there is actually no correlation is very likely wrong). The moderate correlation between the two considered data sets allows only a tentative conjecture that the cirrus distribution maxima derived from the ECMWF reanalyses [Sausen et al., 1998, Figure 6] indicate also where ISSRs might be frequent off the MOZAIC air routes. Maximum ISSR frequencies may be expected over the Indonesian archipelago and over the Amazonas basin, in particular at higher altitudes (near the tropopause) that commercial airliners do not reach (see Plate 2, bottom panels). Another region of presumably high probability for occurrence of ISSRs appears in the northern Pacific between Japan and the Canadian west coast.

\subsection{Correlation Between Subvisible Cirrus and Cirrus From Reanalyses}

Finally, we want to study whether the distribution of SVC in the upper troposphere and lowermost stratosphere is controlled by thermodynamics or whether the presence of suitable ice nuclei is a confining factor. We saw already above (section 3.1) that SVC and ice supersaturation are probably associated, which is an argument for the dominant role of thermodynamics in SVC formation. However, the variation in the composition of the atmospheric aerosol that allows nucleation of SVC ice crystals may contribute to the scatter of data points in Figure 1. Furthermore, the data about ice supersaturation are confined to mainly the northern midlatitudes and we would like to know which is the dominant influence on SVC formation in other regions of the world as well. For this purpose we are now going to compare the SAGE II SVC data with the meteorological analysis data of the ECMWF which we use in the same fashion as before, but now with a greater extension to upper levels in order to reach the tropical tropopause, that is, we include the 100 and $150 \mathrm{hPa}$ levels (which correspond roughly to SAGE II's 16.5 and $14.5 \mathrm{~km}$ altitude levels). The following considerations provide strong arguments for the view that SVC formation is mainly controlled by thermodynamic criteria and not by the presence of suitable aerosol particles.

The top panel of Plate 2 presents the distributions of SVC (from SAGE II) at the four altitude levels 16.5, $14.5,12.5$, and $10.5 \mathrm{~km}$. (The figure contains the same data as Plate 1 of Wang et al. [1996], but with different color coding.) The bottom panel of Plate 2 presents the cirrus coverage that we have derived from the ECMWF reanalysis data in the same fashion as Sausen et al. [1998]. Cirrus coverages are presented at the pressure levels $100,150,200$, and $250 \mathrm{hPa}$. Please note that the SVC distribution is given in terms of "relative frequency of occurrence," whereas the cirrus cover is an areal fractional coverage. Thus the color bar for the SVC distribution extends from 0 to $100 \%$, while that for the cirrus cover extends only from 0 to $50 \%$. A first glance at these distributions shows already a striking similarity of the structures in all four considered layers giving a strong argument in favor of the thermodynamic control of SVC formation.

For the correlation analysis we had first to smooth the ECMWF data to a $24^{\circ} \times 10^{\circ}$ (longitude $\times$ latitude) resolution of the $\mathrm{SAGE}$ data. Further, we have excluded data points with no SVC or no cirrus from the analysis. The result is displayed in Figure 2. As it is already indicated in Plate 2, the correlations are quite strong here: we find correlation coefficients of 0.86 (number of data points $N=88), 0.89(N=$ $134), 0.83(N=213)$, and $0.53(N=225)$ for the $100 \mathrm{hPa} / 16.5 \mathrm{~km}, 150 \mathrm{hPa} / 14.5 \mathrm{~km}, 200 \mathrm{hPa} / 12.5 \mathrm{~km}$, and $250 \mathrm{hPa} / 10.5 \mathrm{~km}$ layers, respectively. In the lowest layer the correlation is 0.80 when only data points from the Southern Hemisphere (south of $-15^{\circ}$, downward pointing triangles in Figure 2) are considered. The low overall correlation in this layer comes from the large scatter of the Northern Hemisphere data (north of $+15^{\circ}$, upward pointing triangles in Figure 2) which have a correlation of 0.53 . All correlations are highly significant, although the scatter in the lowermost layer is quite large.

These results may be interpreted in the following way: SVC formation in the higher altitudes of the troposphere (i.e., tropical SVC) is mainly driven by thermodynamics which implies that suitable ice nuclei should be ubiquitous in these layers. In fact, the very low temperature at the tropical tropopause makes freezing of solution droplets rather insensitive to the chemical composition of the dissolved aerosol, at least in icesupersaturated air masses. In the lowermost layer considered (midlatitude SVC) the situation is more complicated. Whereas the correlation is high in the Southern Hemisphere, it is considerably weaker than anywhere else in the Northern Hemisphere. The reason for this difference could be the following: The midlatitude tropopause region is much warmer than its tropical counterpart, hence the dominant role of thermodynamics seems to be weaker and the nucleation of ice crys- 

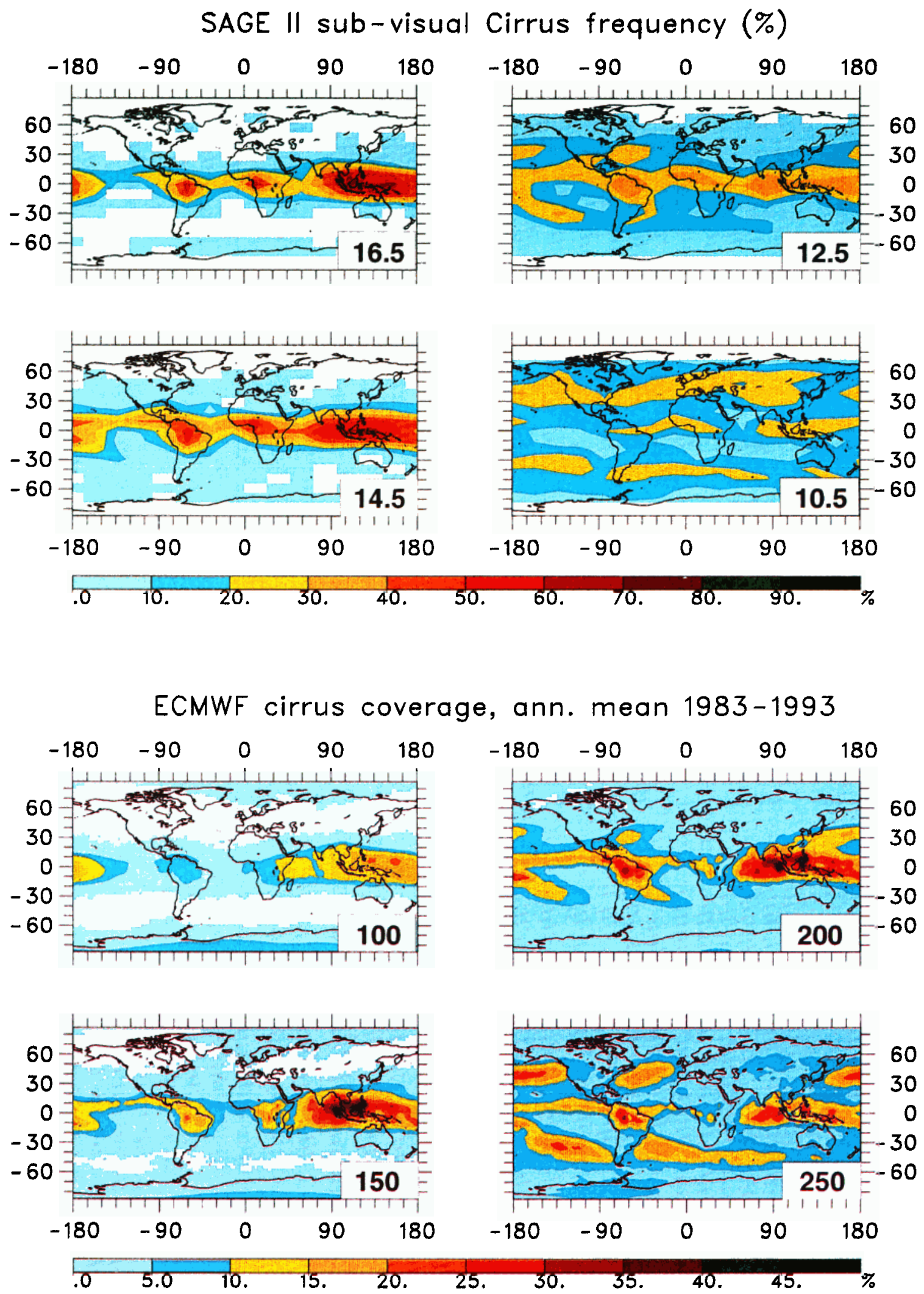

Plate 2. (top) Global distribution of frequency of occurrence of SVC from SAGE II data and (bottom) the ECMWF fractional coverage of cirrus for different altitudes: comparable altitudes are $16.5 \mathrm{~km}$ with $100 \mathrm{hPa}, 14.5 \mathrm{~km}$ with $150 \mathrm{hPa}, 12.5 \mathrm{~km}$ with $200 \mathrm{hPa}$, and $10.5 \mathrm{~km}$ with $250 \mathrm{hPa}$. 

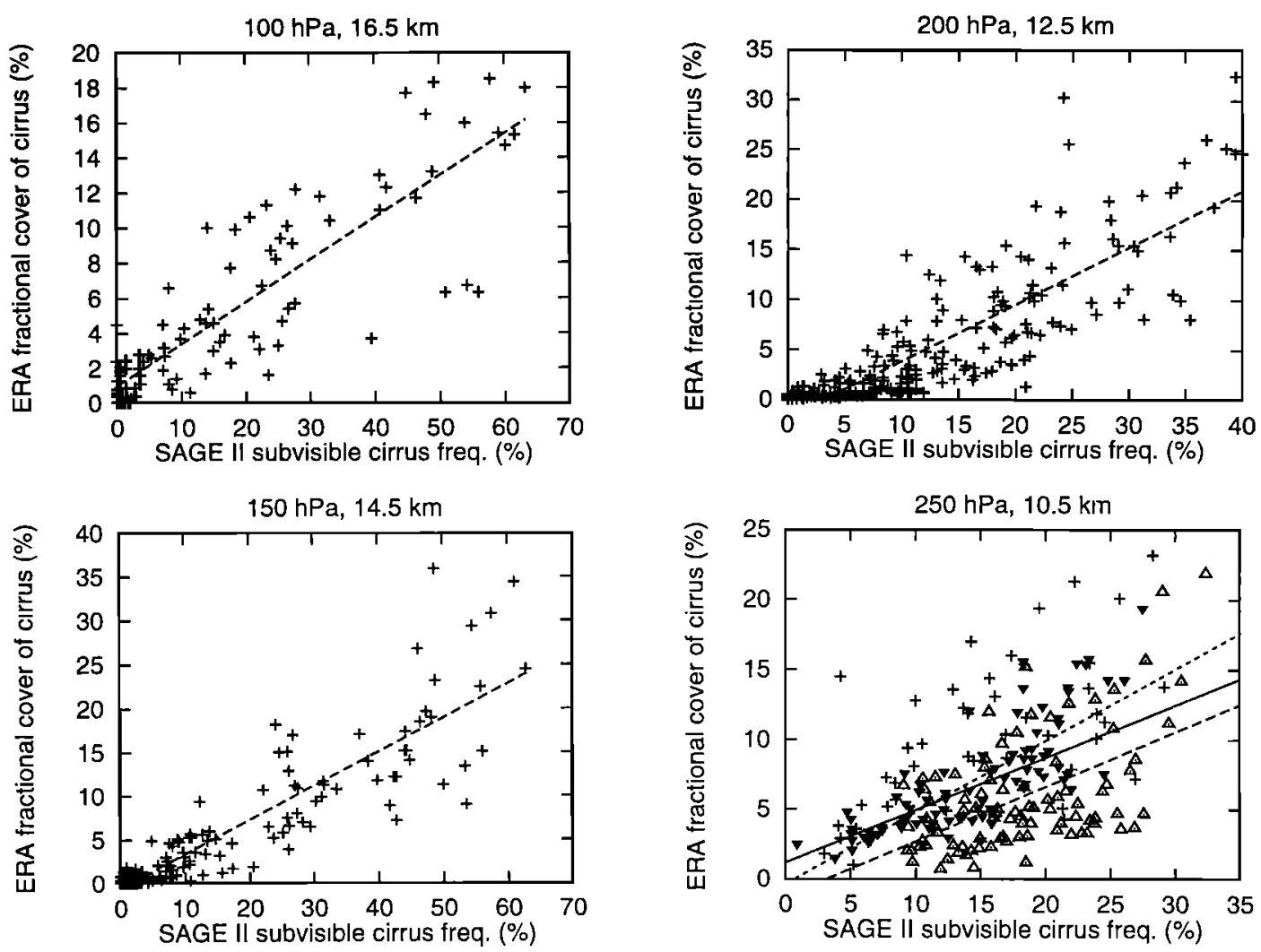

Figure 2. Scatterplot of SAGE II frequency of subvisible cirrus versus the fractional coverage of cirrus from ECMWF reanalyses (ERA data) in the layers centered around $16.5 \mathrm{~km}$ and $100 \mathrm{hPa}$ (top left panel), $14.5 \mathrm{~km}$ and $150 \mathrm{hPa}$ (bottom left), $12.5 \mathrm{~km}$ and $200 \mathrm{hPa}$ (top right), and $10.5 \mathrm{~km}$ and $250 \mathrm{hPa}$ (bottom right). The straight lines represent least squares fits. In the bottom right panel, pluses refer to the equatorial zone $\left(-15^{\circ}\right.$ to $\left.+15^{\circ}\right)$, downward pointing solid triangles refer to the Southern Hemisphere (south of $-15^{\circ}$ ), and upward pointing open triangles refer to the Northern Hemisphere (north of $+15^{\circ}$ ). The solid line is a least squares fit for all data points, the short-dashed line is a fit for the Southern Hemisphere data, and the long-dashed line is a fit for the Northern Hemisphere data.

tals is probably more sensitive to the composition of the aerosol and its freezing properties. It is conceivable that the aerosol at the Northern Hemisphere tropopause is much more variable in its composition than the Southern Hemisphere aerosol due to anthropogenic influence, for example, air traffic. (The investigation of this is currently underway within the European research project interhemispheric differences in cirrus properties from anthropogenic emissions (INCA). For information visit the following web site: http://www.pa.op.dlr.de/inca/) Thus the freezing of a more homogeneous Southern Hemisphere aerosol would again be controlled more by thermodynamics, whereas the freezing of the variable Northern Hemisphere aerosol is at least partly controlled by the aerosol composition and its freezing properties. A further effect could originate from the stronger midlatitudinal instantaneous temperature fluctuations on a $300 \times 300 \mathrm{~km}^{2}$ scale as compared to the tropics [Gierens et al., 1997]. Although there are no data on corresponding fluctuations in the Southern Hemisphere, the more homogeneous land/sea distribution in this re- gion could lead to weaker temperature fluctuations then in the Northern Hemisphere. Such fluctuations would allow small (subgrid) scale SVC formation although the grid scale temperature mean would not, that is, the fluctuations are a further source of the scatter of the data points in the $250 \mathrm{hPa}$ diagram, and the stronger fluctuations in the Northern Hemisphere lead to stronger scatter as compared to the Southern Hemisphere. A general cause of the scatter of the data points in the $250 \mathrm{hPa}$ diagram is the predicted transient nature of midlatitude SVC (compare section 3.1).

\section{Summary and Conclusions}

In the present paper we have investigated the occurrence of ice-supersaturated regions and their relation to subvisible cirrus in the northern midlatitudes. Using humidity and temperature data from MOZAIC, we determined those regions in the upper troposphere where ice supersaturation is frequent. For two $50 \mathrm{hPa}$ thick layers centered around 200 and $250 \mathrm{hPa}$ we have pro- 
duced maps that show the probability of ice supersaturation as functions of longitude and latitude. It was not possible to give a global distribution, though, since the MOZAIC flights are mainly concentrated in the northern midlatitudes. Mean probabilities of ice supersaturation in the covered areas are $11.2 \%$ for the $200 \mathrm{hPa}$ layer and $15.2 \%$ for the $250 \mathrm{hPa}$ layer. Maximum values exceed $33 \%$, for example, over the Atlantic about $10^{\circ}$ west of Brittany in France. These numbers are consistent with earlier determinations of potential contrail coverage [Sausen et al., 1998], which requires ice supersaturation.

The comparison of the MOZAIC ice-supersaturation data with the SAGE II data of subvisible cirrus at midlatitudes gave the strong indication that these phenomena are associated, which is not surprising since it is plausible to assume that the formation of SVC ice crystals needs supersaturation. The probability of occurrence of a certain degree of supersaturation decreases exponentially with supersaturation in ISSRs. Therefore one may conjecture that the formation of SVC starts at only slight supersaturation, perhaps by deposition nucleation, that is, aggregation of water molecules directly from the vapor phase onto suitable nuclei. In contrast to this, the formation of visible cirrus needs more substantial supersaturation [Heymsfield et al., 1998]. In spite of their association with ISSR, midlatitude SVC might be only a transient phenomenon in ISSRs with a much shorter lifetime (hours) compared to that of ISSRs (synoptic timescale, i.e., some days).

In order to derive a global picture of ISSR occurrence one must, regarding the lack of global MOZAIC-like data, try to connect the MOZAIC data with global data sets of upper tropospheric humidity or cirrus coverage. Here we tried for that purpose cirrus distributions constructed by Sausen et al. [1998] from ECMWF reanalyses. Unfortunately, the correlation between the data sets is moderate $(\approx 0.3)$, so that locations of frequent ice supersaturation off the MOZAIC air routes can only be tentatively inferred from this cirrus data set. We might expect high ISSR frequencies over the Indonesian archipelago, over the Amazonas basin, and in the northern Pacific between Japan and the Canadian west coast. To derive a more reliable global picture of the occurrence of ISSRs, it should be useful to employ appropriate satellite data of temperature and upper tropospheric humidity. The connection of the MOZAIC data with such satellite data is therefore highly desirable and planned as future work.

Finally, we compared the SAGE II SVC data with the cirrus coverage data derived from the ECMWF reanalyses. The purpose of this exercise was to determine whether the formation of SVC is thermodynamically controlled or whether the availability of suitable ice nuclei is a confining factor. From the spatial distributions of SVC and cirrus (Plate 2) we found already a strong argument in favor of the thermodynamic control. This was confirmed by the correlation analysis which gave rather high coefficients $(r>0.8)$ for all but the lowermost considered layer $(250 \mathrm{hPa} / 10.5 \mathrm{~km}, r \approx 0.5)$. The larger scatter in the $250 \mathrm{hPa} / 10.5 \mathrm{~km}$ layer (which mainly represents midlatitude SVC) originates from the Northern Hemisphere data alone $(r=0.53)$, whereas the corresponding data for the Southern Hemisphere again show a high correlation $(r=0.80)$. A potential reason for this difference is a more variable aerosol composition in the northern midlatitude tropopause region than in the southern midlatitudes due to anthropogenic influences (e.g., air traffic). The upper tropospheric temperature is higher at midlatitudes than in the tropics and therefore SVC formation at midlatitudes may depend more strongly on the freezing properties of the aerosol. Another possible contribution of the scatter of the data are larger instantaneous small-scale temperature fluctuations in the northern than in the Southern Hemisphere (where we have unfortunately no data on this). A general source to the data scatter in the $250 \mathrm{hPa}$ layer can be the short lifetime of midlatitude SVC compared to the lifetime of ice-supersaturated regions.

ISSRs have not attracted much interest during the recent 50 years, and research on SVC is now beginning to appear, though mostly confined to the tropical species. Hence there are many open questions: What is the critical supersaturation for SVC formation? Which are the suitable nuclei for that process? Which kind of nucleation occurs? How does SVC evolve within an ISSR? Are lifetimes of midlatitude SVC and ISSR different? Is SVC really a transient phenomenon? Although SVC is, by definition, invisible looking vertically from the ground, it is a widespread, ubiquitous, and frequent scatterer of radiation in the coldest part of the lower atmosphere, and may thus have a significant influence on the energy balance of the globe, hence on climate. It should receive a high research priority, and the questions formulated above should be addressed in experimental flight campaigns in combination with evaluation of satellite data sets and microphysical simulations.

Acknowledgments. The authors thank Bernd Kärcher for fruitful discussions. $K$. Gierens is supported by the Aerosolforschungsschwerpunkt (AFS) of the Bundesministerium für Bildung und Forschung. P.-H. Wang is supported by NASA contract NAS1-99129. The ERA data were provided by ECMWF within the Special Project "The climatology of the global tropopause." The project MOZAIC is funded by the Commission of the European Union and coordinated by Alain Marenco (Toulouse).

\section{References}

Bakan, S., M. Betancor, V. Gayler, and H. Grassl, Contrail frequency over Europe from NOAA-satellite images, $A n n$. Geophys., 12, 962-968, 1994.

Carleton, A.M., and P.J. Lamb, Jet contrails and cirrus cloud: A feasiliiity study employing high-resolution satellite imagery, Bull. Am. Meteorol. Soc., 67, 301-309, 1986.

Gibson, J.K., P. Kallberg, S. Uppala, A. Hernandez, A. 
Nomura, and E. Serrano, ERA Description, ERA PRS1, ECMWF, Reading, UK, 1997.

Gierens, K., and P. Spichtinger, On the size distribution of ice-supersaturated regions in the upper troposphere and lowermost stratosphere, Ann. Geophys., 18, 499-504, 2000.

Gierens, K.M., U. Schumann, H.G.J. Smit, M. Helten, and G. Zängl, Determination of humidity and temperature fluctuations based on MOZAIC data and parametrisation of persistent contrail coverage for general circulation models, Ann. Geophys., 15, 1057-1066, 1997.

Gierens, K., U. Schumann, M. Helten, H. Smit, and A. Marenco, A distribution law for relative humidity in the upper troposphere and lower stratosphere derived from three years of MOZAIC measurements, Ann. Geophysicae, 17, 1218-1226, 1999

Hall, W.D., and H.R. Pruppacher, The survival of ice particles falling from cirrus clouds in subsaturated air, J. Atmos. Sci., 33, 1995-2006, 1976.

Helten, M., H.G.J. Smit, W. Sträter, D. Kley, P. Nedelec, M. Zöger, and R. Busen, Calibration and performance of automatic compact instrumentation for the measurement of relative humidity from passenger aircraft, J. Geophys. Res., 103, 25,643-25,652, 1998.

Helten, M., H.G.J. Smit, D. Kley, J. Ovarlez, H. Schlager, R. Baumann, U. Schumann, P. Nedelec, and A. Marenco, In-flight intercomparison of MOZAIC and POLINAT water vapor measurements, J. Geophys. Res., 104, 26,08726,096, 1999.

Heymsfield, A.J., L.M. Miloshevich, C. Twohy, G. Sachse, and S. Oltmans, Upper-tropospheric relative humidity observations and implications for cirrus ice nucleation, Geophys. Res. Lett., 25, 1343-1346, 1998.

Jensen, E J., O B. Toon, H.B. Selkirk, J.D Spinhirne, and M.R. Schoeberl, On the formation and persistence of subvisible cirrus clouds near the tropical tropopause, $J$. Geophys. Res., 101, 21,361-21,375, 1996.

Lindzen, R.S., Some coolness concerning global warming, Bull. Am. Meteorol. Soc., 71, 288-299, 1990.

Lynch, D.K., Subvisual cirrus: What it is and where you find it, in Passive Infrared Remote Sensing of Clouds and the Atmosphere, edited by D.K. Lynch, Proc. SPIE Int. Soc. Opt. Eng., 1934, 264-274, 1993.

Mannstein, H., R. Meyer, and P. Wendling, Operational detection of contrails from NOAA-AVHRR-data, Int. $J$. Remote Sens., 20, 1641-1660, 1999.

Marenco, A., et al., Measurement of ozone and water vapor by Airbus in-service aircraft: The MOZAIC airborne program, an overview, J. Geophys. Res., 103, 25,631-25,642, 1998.

Murphy, D.M., K.K. Kelly, A.F. Tuck, M.H. Proffitt, and $\mathrm{S}$. Kinne, Ice saturation at the tropopause observed from the ER-2 aircraft, Geophys. Res. Lett., 17, March suppl., 353-356, 1990.

Ovarlez, J., P. van Velthoven, G. Sachse, S. Vay, H. Schlager, and $\mathrm{H}$. Ovarlez, Comparison of water vapor measurements from POLINAT 2 with ECMWF analyses in high humidity conditions, J. Geophys. Res., 105, 3737-3744, 2000.
Ramanathan, V., and W. Collins, Thermodynamic regulation of ocean warming by cirrus clouds deduced from observations of the 1987 El Niño, Nature, 351, 27-32, 1991.

Rind, D., E.W. Chiou, W. Chu, J. Larsen, S. Oltmans, J. Lerner, M.P. McCormick, and L. McMaster, Positive water vapour feedback in climate models confirmed by satellite data, Nature, 349, 500-503, 1991.

Sassen, K., and B.S. Cho, Subvisual-thin cirrus lidar dataset for satellite verification and climatological research, $J$. Appl. Meteorol., 31, 1275-1285, 1992.

Sassen, K., M.K. Griffin, and G.C. Dodd, Optical scattering and microphysical properties of subvisual cirrus clouds, and climatic implications, J. Appl. Meteorol., 28, 91-98, 1989.

Sausen, R., K. Gierens, M. Ponater, and U. Schumann, A diagnostic study of the global distribution of contrails, I, Present day climate, Theor. Appl. Climatol., 61, 127$141,1998$.

Schmidt, E.O., J.M. Alvarez, M.A. Vaughan, and D.P. Wylie, A review of subvisual cirrus morphology, in Passive Infrared Remote Sensing of Clouds and the Atmosphere, edited by D.K. Lynch, Proc. SPIE Int. Soc. Opt. Eng., 1934, 230-239, 1993.

Schumann, U., On conditions for contrail formation from aircraft exhausts, Meteorol. Z., 5, 4-24, 1996.

Schumann, U., H. Schlager, F. Arnold, J. Ovarlez, H. Kelder, $\varnothing$. Hov, G. Hayman, I.S.A. Isaksen, J. Staehelin, and P.D. Whitefield, Pollution from aircraft emissions in the North Atlantic flight corridor: Overview on the POLINAT projects, J. Geophys. Res., 105, 3605-3631, 2000.

Sussmann, R., and K. Gierens, Lidar and numerical studies on the different evolution of vortex pair and secondary wake in young contrails, J. Geophys. Res., 104, 21312142, 1999.

Thuburn, J, and G.C. Craig, GCM tests of theories for the height of the tropopause, J. Atmos. Sci., 54, 869-882, 1997.

Wang, P., P. Minnis, M.P. McCormick, G.S. Kent, and K.M. Skeens, A 6-year climatology of cloud occurence frequency from Stratospheric Aerosol and Gas Experiment II observations (1985-1990), J. Geophys. Res., 101, 29,407$29,429,1996$.

Weickmann, H., Formen und Bildung atmosphärischer Eiskristalle, Beitr. Phys. Atmos., 28, 12-52, 1945.

K. Gierens and U. Schumann, Deutsches Zentrum für Luft- und Raumfahrt, Institut für Physik der Atmosphäre, Oberpfaffenhofen, D-82234 Wessling, Germany. (klaus.gierens@dlr.de)

M. Helten and H. Smit, Forschungszentrum Jülich, Institut für Chemie der belasteten Atmosphäre (ICG2), Postfach 1913, D-52425 Jülich, Germany.

P.-H. Wang Science and Technology Corporation, 101 Research Drive, Hampton, VA 23666-1340.

(Received October 14, 1999; revised March 17, 2000; accepted May 21, 2000.) 